\title{
Disability in Moderate Chronic Obstructive Pulmonary Disease: Prevalence, Burden and Assessment - Results from a Real-Life Study
}

\author{
Fulvio Braido $^{a} \quad$ Ilaria Baiardini $^{a} \quad$ Nicola Scichilone $^{b} \quad$ Claudio Sorino $^{b, c}$ \\ Fabiano Di Marco ${ }^{d}$ Angelo Corsico ${ }^{f}$ Pierachille Santus $^{\mathrm{e}}$ \\ Giuseppe Girbino $^{g}$ Giuseppe Di Mariah ${ }^{\text {h }}$ Carlo Mereu ${ }^{i}$ Eugenio Sabato ${ }^{j}$ \\ Maria Pia Foschino Barbarok Giuseppina Cuttittal Alberto Zolezzim \\ Caterina Bucca $^{\mathrm{n}}$ Sara Balestracci ${ }^{\mathrm{a}}$ Giorgio Walter Canonica ${ }^{\mathrm{a}}$
}

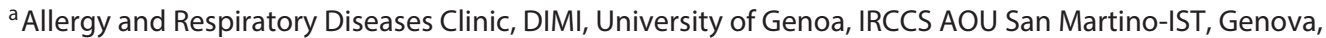
bDipartimento Biomedico di Medicina Interna e Specialistica, University of Palermo, 'Villa Sofia-Cervello' Hospital, Palermo, 'Pulmonology Unit, AO Sant'Anna, Como, ${ }^{\mathrm{d}}$ Clinica di Malattie Respiratorie, UOC Pneumologia, Ospedale San Paolo, and 'Università degli Studi di Milano, Pneumologia Riabilitativa, Fondazione Salvatore Maugeri, Istituto Scientifico di Riabilitazione di Milano (IRCCS), Milan, ${ }^{f}$ Dipartimento di Medicina Molecolare, Fondazione IRCCS Policlinico San Matteo, Università di Pavia, Pavia, ${ }^{9}$ Respiratory Department, University Hospital, Messina, ${ }^{\mathrm{h}}$ School of Specialization in Respiratory Diseases, University of Catania, Catania, 'Pulmonology Department, Santa Corona Hospital, Pietra Ligure, Savona, 'Department of Pneumology and Respiratory Rehabilitation 'A. Blasi', Brindisi, ${ }^{k}$ Institute of Respiratory Disease, Medical and Surgical Sciences Department, University of Foggia, Foggia, 'Pulmonary Environmental Epidemiology Unit, CNR Institute of Clinical Physiology, Pisa, ${ }^{m}$ Pulmonology Unit, AOU Carlo Poma, Mantova, and ${ }^{\mathrm{n}}$ Department of Medical Sciences, University of Turin, Turin, Italy
\end{abstract}

\section{Key Words}

Chronic obstructive pulmonary disease - Disability .

Patient-reported outcomes

\begin{abstract}
Background: The role of disability and its association with patient-reported outcomes in the nonsevere forms of chronic obstructive pulmonary disease (COPD) has never been explored. Objectives: The aim of this study was to assess, in a cross-sectional real-life study, the prevalence and degree of disability in moderate COPD patients and to assess its association with health status, illness perception, risk of death and well-being. Methods: Moderate COPD outpatients attending scheduled visits were involved in a quantitative re-
\end{abstract}

search program using a questionnaire-based data collection method. Results: Out of 694 patients, $17.4 \%$ were classified as disabled and $47.6 \%$ reported the loss of at least one relevant function of daily living. Disabled patients did not differ from nondisabled patients in terms of working status ( $p=$ $0.06)$, smoking habits $(p=0.134)$ and ongoing treatment $(p=$ 0.823); however, the former showed a significantly higher disease burden as measured by illness perception, health status and well-being. The stepwise regression analysis showed that the modified Medical Research Council (mMRC) score was the most relevant factor related to COPD disability $(F=38.248 ; p=0.001)$. Patient stratification was possible according to the forced expiratory volume in $1 \mathrm{~s}\left(\mathrm{FEV}_{1}\right)$ value and an $\mathrm{mMRC}$ score $\geq 2$, which identified disabled patients, whereas the $\mathrm{mMRC}$ values were differently associated with

\section{KARGER 125}

(c) 2015 S. Karger AG, Base

$0025-7931 / 15 / 0892-0100 \$ 39.50 / 0$

E-Mail karger@karger.com

www.karger.com/res
Prof. Fulvio Braido

Allergy and Respiratory Diseases Clinic, DIMI

University of Genoa, IRCCS AOU San Martino-IST

Pad. Maragliano, Largo Rosanna Benzi 10, IT-16132 Genova (Italy)

E-Mail fulvio.braido@ unige.it 
the risk of disability. Conclusion: A significant proportion of individuals with moderate COPD reported a limitation of daily life functions, with dyspnea being the most relevant factor inducing disability. Adding the evaluation of patient-reported outcomes to lung function assessment could facilitate the identification of disabled patients. @ $2015 \mathrm{~S}$. Karger AG, Basel

\section{Introduction}

Chronic obstructive pulmonary disease (COPD) is considered as a heterogeneous disease, and forced expiratory volume in $1 \mathrm{~s}\left(\mathrm{FEV}_{1}\right)$ does not fully describe its complexity [1]. In 2011, the Global Initiative for Chronic Obstructive Lung Disease (GOLD) recommendations [1] proposed for the first time a multidimensional approach that included both functional parameters and patient-reported outcomes, with the aim to provide a comprehensive assessment of the disease, thus meeting both the needs of the patient and the role of the physician. However, the prognostic and clinical implications of this classification, which integrates patients' and physicians' perspectives, need to be clearly understood.

Several studies analyzed existing cohorts of COPD subjects to explore different aspects of the GOLD 2011 [1] assessment proposal. Han et al. [2] used the COPDGene cohort [3] to investigate the influence of choosing different tools on severity group assignment and the risk of exacerbations during the follow-up period, showing that the choice of a specific measurement of the respiratory symptoms, that is, dyspnea [modified Medical Research Council (mMRC)] versus health status [St. George's Respiratory Questionnaire (SGRQ) as a surrogate for the COPD Assessment Test (CAT)], can significantly change the category assignment. Lange et al. [4] investigated the ability of the GOLD 2011 proposal [1] to predict the clinical course of the disease, showing that both prebronchodilator spirometric GOLD grades and the ABCD GOLD 2011 [1] classification predicted mortality in the general population, however, without exploring which approach best applied to it. Similar findings were obtained by Soriano et al. [5], who analyzed pooled data from eleven Spanish cohorts followed for at least 10 years, and by the GenKOLS cohort study in which COPD patients were followed for 8 years [6]. Both studies failed to demonstrate any difference between the GOLD lung function classification and the ABCD classification in predicting mortality. In contrast, Leivseth et al. [7] showed that the ABCD classification was less sen- sitive in predicting mortality compared to the lung function classification.

Besides mortality, other relevant outcomes such as disability need to be fully evaluated in COPD patients. This is what emerges from a recent editorial by Yohannes [8] that underlines the necessity to properly assess the limitations in daily activities in order to help physicians to design tailored interventions for patients with COPD. It has been previously shown that a significant percentage of disabled patients can be identified in each disease stage, with dyspnea serving as the most relevant factor inducing disability [9]. A systematic review of 65 studies shows that patients with a moderate disease severity are the most frequent in the whole population of COPD [10]. In this respect, the assessment of the prevalence of disability and its association with patient-reported outcomes in less severe COPD patients is a prerequisite for planning specific behavioral, educational and therapeutic interventions. If deterioration is not detected early, besides increasing the burden of the disease in the early stages, it may lead the patient to require assistance to maintain independence at home [8]. It is possible to evaluate the limitations of physical activity in moderate COPD patients [11] in order to monitor the impact of disease and therapeutic interventions. The aim of the present study was to assess the prevalence and degree of disability in moderate COPD patients according to the GOLD 2007 [12] classification of severity and to assess its association with health status, illness perception, risk of death and well-being. Furthermore, we evaluated whether the addition of an mMRC cutoff $(\geq 2$ or $<2)$ to spirometric parameters provides additional advantages for discriminating different populations in terms of disease impact on patients' life.

\section{Materials and Methods}

\section{Study Design and Patients}

A quantitative research program using a questionnaire data collection method was performed. The study population included adult patients with physician-diagnosed moderate COPD according to the GOLD 2007 guidelines (stage II: $50 \%<\mathrm{FEV}_{1} \leq 80 \%$ ) [12], attending 18 academic and/or hospital centers for follow-up visits from April to December 2011. While waiting for the visit, patients were invited to fill in questionnaires regarding their illness perception, health status and well-being. The inclusion criteria were the comprehension of written and spoken Italian language and the availability for participation in the study. Exclusion criteria were lack of knowledge of the Italian language, presence of impaired cognitive functions and visual-auditory defects, physical inability to autonomously complete the questionnaire, presence of asthma or respiratory diseases other than COPD. This study was performed according to Good Clinical Practice standards and the 
Declaration of Helsinki and was approved by the local ethics committee, and all patients gave their written informed consent. During the visit, patients underwent postbronchodilator spirometry (European Respiratory Society - American Thoracic Society guidelines) [13]. Each patient was invited to complete the following questionnaires:

- The Barthel activities of daily living (ADL) index [14], which evaluates the self-sufficiency of the patient by means of 10 items describing the ADL and the ability to move. The score of each item may be $0,5,10$ or 15 ; higher scores are associated with a greater likelihood of being able to live at home.

- The Lawton instrumental ADL (IADL) scale [15], which assesses a person's ability to perform different tasks (using a telephone, doing laundry, handling finances, preparing meals, home management, using transportation, shopping and adhere to therapy). It provides a global score ranging from 0 (low function) to 8 (high function).

- The Charlson comorbidity index [16], which is used to estimate the risk of mortality at 1 year in patients affected by different comorbidities that may influence the long-term survival. It includes 19 medical conditions weighted from 1 to 6 with a total score ranging from 0 to 37 . From the weighted conditions, a sum score can be tallied to yield the total comorbidity score.

- The mMRC dyspnea scale [17], which is used to evaluate dyspnea and its effect on the daily activities. This is a simple, standardized scale consisting of 5 statements that describe the range of respiratory disability, from no disability at all (stage 1: 'I only get breathless with strenuous exertion') to almost complete incapacity (stage 5: 'I am too breathless to leave the house').

- The Illness Perception Questionnaire (IPQ-R) [18], which is used to evaluate patients' opinion and understanding of the disease. It is divided into two parts: the first one describes the presence of symptoms and the identification by the patient of the potential relationship between each symptom and the disease; the second part investigates the following factors: consequences, timeline acute/chronic, timeline cyclical, illness coherence, personal control, treatment control and emotional representation.

- The Psychological General Well-Being Index (PGWBI) [19], which measures the subjective perception of well-being. This self-administered index is rated on a 6-point scale and consists of 22 items assessing the psychological and general well-being in 6 domains: anxiety, depressed mood, positive well-being, self-control, general health and vitality. Adding the scores of the 6 dimensions investigated, a summery distress index (0-60 points $=$ severe distress; $61-72$ points $=$ moderate distress; $73-$ 97 points $=$ no distress; $>98$ points $=$ positive well-being; 110 points = best-achievable well-being) can be obtained.

- The SF-12 Health Survey [20], which is used to assess health status. It consists of 12 items (obtained by 36 items of questionnaire SF-36) that provide two measures: Physical Component Summary and Mental Component Summary. The scores range from 0 to 100, where a zero score indicates the lowest level of health measured by the scales and 100 indicates the highest level of health.

\section{Sample Size and Statistical Analysis}

A total of 18 centers, homogeneously distributed across Italy, were asked to recruit the first 50 consecutive moderate COPD patients attending their clinic for a routine visit in a 6-month pre-

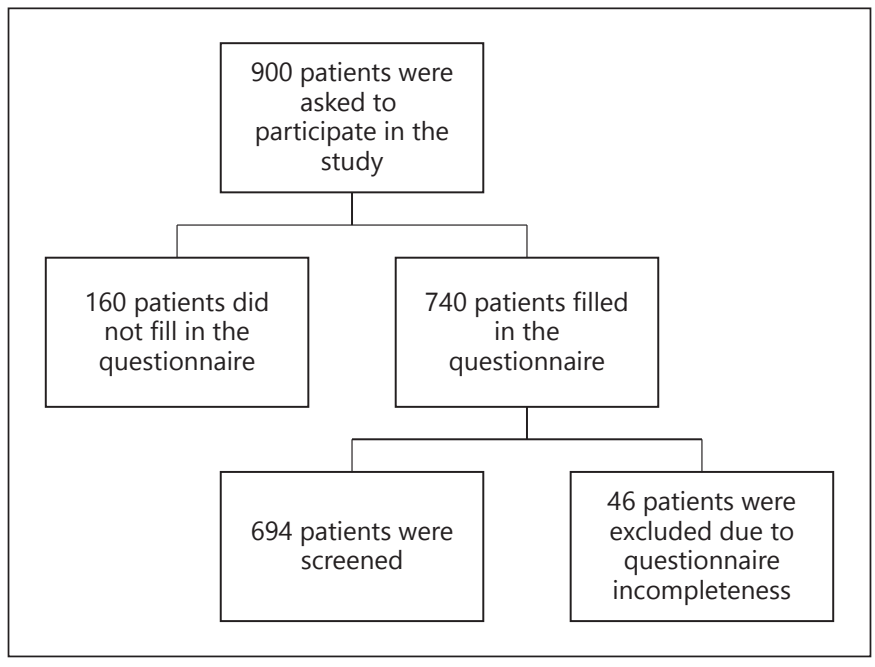

Fig. 1. Procedure of patient enrollment.

defined period. The recruitment of a minimum of 650 patients was considered sufficient to explore the aim of the study. The sample size was estimated considering a $20 \%$ data failure due to patients and physicians failing to fill in the questionnaire and the prevalence of moderate COPD in patients attending hospital clinics. Analyses were conducted in the overall population and in two subpopulations defined according to the mMRC score $(\geq 2$ or $<2)$.

For the purpose of the study, patients were classified on the basis of their Barthel score into self-sufficient (ADL score $=100)$ and disabled (ADL score $<100)$. The latter were stratified into 4 degrees of disability: mild (score 91-99), moderate (61-90), severe (21-60) and very severe (0-20).

The results are shown as means (standard deviations; SD), unless otherwise stated. Student's t test was used to detect significant differences of quantitative variables, while the $\chi^{2}$ test was used to detect significant differences of qualitative variables. Spearman's $\rho$ was applied to test the relationship between variables or rank scores. Linear regression was used to estimate the coefficients of the equation that provided the best value of the dependent variables.

\section{Results}

\section{Overall Population Analysis}

Out of the 900 COPD patients who were asked to participate in the study, 740 filled in the questionnaires. Only the questionnaires of patients with a $>90 \%$ completion rate $(n=694)$ were considered for analysis (fig. 1$)$. The sociodemographic and functional characteristics of the study sample are reported in table 1.

The Barthel index revealed that $17.4 \%$ of patients had features of disability at different levels: $12.3 \%$ had mild, $2.5 \%$ had moderate, $1.9 \%$ had severe and $0.7 \%$ had very 
Table 1. Sociodemographic characteristics of the study COPD population $(\mathrm{n}=694)$

\begin{tabular}{ll}
\hline Characteristics & \\
\hline Mean age \pm SD, years & $70.23 \pm 9.7$ \\
Male sex, \% & 74.9 \\
Mean FEV \pm SD, \% & $64.09 \pm 9.07$ \\
mMRC score, \% & \\
1 & 15.6 \\
2 & 36.7 \\
3 & 23.7 \\
4 & 19.4 \\
5 & 4.6 \\
Mean BMI \pm SD & $27.57 \pm 5.06$ \\
Smoking habits, \% & \\
Current smokers & 27.8 \\
Nonsmokers & 9.7 \\
Former smokers & 62.5 \\
Education, \% & 49.6 \\
Primary school & 26.5 \\
Secondary school & 19.1 \\
High school & 4.8 \\
Degree & \\
Employment status, \% & 15.3 \\
Workers & 84.7 \\
Retired & \\
Ongoing therapies, \% & 16.6 \\
Short-acting $\beta_{2}$ agonist & 15.1 \\
Long-acting $\beta_{2}$ agonist & 54.4 \\
Long-acting muscarinic antagonists & \\
Inhaled corticosteroids in association & 58.4 \\
$\quad$ with long-acting bronchodilators & 4.5 \\
Oral theophylline & \\
Oral corticosteroids & \\
Long-term oxygen therapy & \\
\hline & \\
\hline
\end{tabular}

severe disability. According to the IADL scale responses, no function was lost by $52.4 \%$ of patients; $16.2 \%$ of patients lost 1 function, $10.5 \%$ lost 2 functions, $8.2 \%$ lost 3 functions and $13 \%$ lost between 4 and 8 functions. According to the mMRC, 15.6, 36.7, 23.7, 19.4 and $4.6 \%$ of patients belonged to the 1-5 levels of dyspnea, respectively. The Charlson index mean values were as follows: Charlson weighted index of comorbidity $2.26 \pm 1.52$; Charlson age-related risk $4.83 \pm 1.93$; Charlson combined comorbidity index and age-related risk $36.59 \pm$ 32.49 .

\section{Population Analysis According to Disability}

Compared to nondisabled patients, disabled subjects had a statistically significant lower level of education $\left(\chi^{2}=\right.$ 21.21; $\mathrm{p}<0.001)$ but did not differ for working status $\left(\chi^{2}=\right.$ 3.47; $\mathrm{p}=0.06)$, smoking habits $\left(\chi^{2}=4.01 ; \mathrm{p}=0.134\right)$, use
Table 2. Comparison of clinical parameters, illness perception, health status and well-being in disabled and nondisabled patients

\begin{tabular}{|c|c|c|c|}
\hline & $\begin{array}{l}\text { Disabled } \\
\text { patients }^{\mathrm{a}}\end{array}$ & $\begin{array}{l}\text { Nondisabled } \\
\text { patients }^{b}\end{array}$ & $\begin{array}{l}\text { Significance } \\
\text { (two-tailed) }\end{array}$ \\
\hline $\mathrm{FEV}_{1}$ & $62.7(8.6)$ & $64.3(9.1)$ & 0.072 \\
\hline Charlson index & $15.4(25.3)$ & $41.0(32.1)$ & $0.001^{\mathrm{a}}$ \\
\hline mMRC dyspnea & $3.6(0.9)$ & $2.4(1.0)$ & $0.001^{\mathrm{a}}$ \\
\hline \multicolumn{4}{|l|}{$I P Q-R$} \\
\hline Identity & $4.55(2.4)$ & $3.3(2.3)$ & $<0.001^{\mathrm{a}}$ \\
\hline Timeline & $22.9(4.4)$ & $22.6(4.6)$ & 0.346 \\
\hline Consequences & $20.6(4.4)$ & $17.8(4.1)$ & $<0.001^{\mathrm{a}}$ \\
\hline Personal control & $18.2(3.8)$ & $19.7(3.8)$ & $<0.001^{\mathrm{a}}$ \\
\hline Treatment control & $17.3(3.1)$ & $18.2(2.9)$ & $0.005^{\mathrm{a}}$ \\
\hline Illness coherence & $16.0(3.9)$ & $17.8(3.9)$ & $<0.001^{\mathrm{a}}$ \\
\hline Timeline cyclical & $13.7(2.9)$ & $11.8(3.3)$ & $<0.001^{\mathrm{a}}$ \\
\hline \multicolumn{4}{|l|}{ Emotional } \\
\hline representations & $18.9(4.5)$ & $15.9(4.6)$ & $<0.001^{\mathrm{a}}$ \\
\hline \multicolumn{4}{|l|}{$P G W B I$} \\
\hline Anxiety & $14.7(4.8)$ & $17.8(4.7)$ & $<0.001^{\mathrm{a}}$ \\
\hline Depressed mood & $9.4(3.5)$ & $11.8(3.1)$ & $<0.001^{\mathrm{a}}$ \\
\hline Positive well-being & $8.3(3.6)$ & $11.3(3.9)$ & $<0.001^{\mathrm{a}}$ \\
\hline Self-control & $8.6(3.2)$ & $11.5(3.2)$ & $<0.001^{\mathrm{a}}$ \\
\hline General health & $7.1(3.3)$ & $9.7(3.2)$ & $<0.001^{\mathrm{a}}$ \\
\hline Vitality & $8.2(3.6)$ & $12.1(5.9)$ & $<0.001^{\mathrm{a}}$ \\
\hline Global score & $56.4(18.1)$ & $73.8(18.8)$ & $<0.001^{\mathrm{a}}$ \\
\hline \multicolumn{4}{|l|}{$S F-12$} \\
\hline Physical component & $30.3(7.8)$ & $38.9(9.4)$ & $<0.001^{\mathrm{a}}$ \\
\hline Mental component & $39.6(11.5)$ & $47.2(11.5)$ & $<0.001^{\mathrm{a}}$ \\
\hline
\end{tabular}

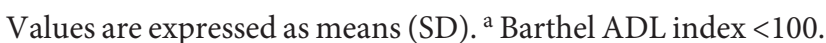
${ }^{\mathrm{b}}$ Barthel ADL index $=100 .{ }^{*} \mathrm{p} \leq 0.01$.

of short-acting $\beta_{2}$ agonists $\left(\chi^{2}=0.21 ; p=0.647\right)$ and treatment $\left(\chi^{2}=0.911 ; \mathrm{p}=0.823\right)$.

The Lawton IADL scores showed that a significantly higher number of disabled patients lost the ability to use the telephone $\left(\chi^{2}=33.09 ; \mathrm{p}<0.001\right)$, to take care of shopping needs independently $\left(\chi^{2}=207.53 ; \mathrm{p}<0.001\right)$, to adequately take care of nutrition $\left(\chi^{2}=106.94 ; \mathrm{p}<0.001\right)$, to manage their house needs $\left(\chi^{2}=43.509 ; \mathrm{p}<0.001\right)$, to do the laundry $\left(\chi^{2}=52.286\right.$; $\left.\mathrm{p}<0.001\right)$, to travel independently on public transport or to drive a car $\left(\chi^{2}=94.299\right.$; $\mathrm{p}<0.001)$, to take responsibility for their own medications $\left(\chi^{2}=138.330 ; \mathrm{p}<0.001\right)$ and to handle finances $\left(\chi^{2}=\right.$ 29.928; $\mathrm{p}<0.001)$.

As regards clinical findings and IPQ-R, SF-12 and PGWBI questionnaire scores, the comparison between disabled and nondisabled patients showed significant differences between the two groups, as reported in table 2 . 


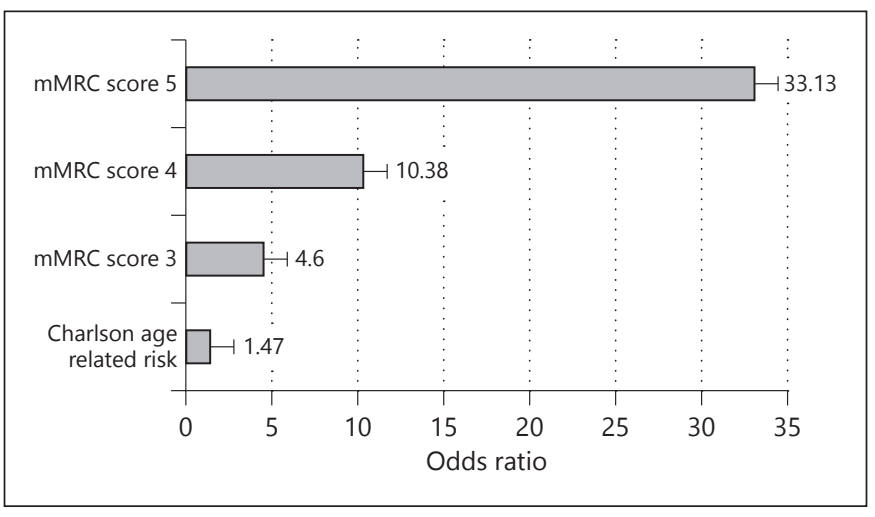

Fig. 2. Estimated odds ratio of being disabled according to the mMRC score and the Charlson age-related risk.

However, when the stepwise regression analysis was performed, the mMRC score remained the only factor associated with COPD disability $(\mathrm{F}=38.248 ; \mathrm{p}=0.001)$.

Population Analysis According to mMRC Cutoff Score

A vast proportion of the 694 patients that were evaluated showed an mMRC score $\geq 2(84.4 \%)$ and the median $\mathrm{mMRC}$ value was 2 . Among the patients with an mMRC score $\geq 2,20.3 \%$ were disabled. The comparison between disabled and nondisabled patients in the group of subjects with an mMRC score $\geq 2$ showed that disabled patients were significantly older $(\mathrm{p}<0.001)$, had a greater risk of death defined by the Charlson index $(\mathrm{p}<0.001)$, showed worse well-being and health status $(\mathrm{p}<0.001)$ as well as higher levels of anxiety/depression $(\mathrm{p}<0.001)$. No differences between disabled and nondisabled patients were found concerning airway obstruction $\left(\mathrm{FEV}_{1} \%\right.$ predicted $)$ and BMI.

The stepwise regression analysis showed that in COPD patients with $\geq 50 \% \mathrm{FEV}_{1}$ predicted and $\leq 80 \% \mathrm{FEV}_{1}$ predicted and an mMRC score $\geq 2$, the mMRC value was the most relevant factor for predicting COPD disability $(\mathrm{F}=$ $63.48 ; \mathrm{p}=0.001)$. The increase in mMRC score was significantly related to the increase in disability. In particular, the odds ratio of being disabled was 4.6 for an mMRC score of 3, 10.38 for an mMRC score of 4 and 33.13 for an mMRC score of 5 (while the Charlson age-related risk odds ratio was 1.47; fig. 2 ).

Using a median score of 2 as a cutoff, 330 patients had mMRC scores of 3, 4 or 5 . Among them, 20.3\% were disabled. Again, the comparison between disabled and nondisabled patients in the group of subjects with an mMRC score of 3, 4 or 5 showed that disabled patients were significantly older $(\mathrm{p}<0.001)$, had a greater risk of death defined by the Charlson index $(\mathrm{p}<0.001)$, showed worse well-being and health status $(\mathrm{p}<0.001)$ as well as higher levels of anxiety/depression $(\mathrm{p}<0.001)$. No differences between disabled and nondisabled patients were found concerning airway obstruction $\left(\mathrm{FEV}_{1} \%\right.$ predicted) and BMI.

The stepwise regression analysis showed that in COPD patients with $\geq 50 \mathrm{FEV}_{1} \%$ predicted $\leq 80$ and an $\mathrm{mMRC}$ score $\geq 2$, the mMRC score was the most relevant factor for predicting COPD disability $(\mathrm{F}=23.03 ; \mathrm{p}<0.001)$. Moreover, the Charlson age-related risk odds ratio was 2.5 .

\section{Discussion}

The present study focused on disability prevalence, burden and assessment in individuals with moderate COPD according to the GOLD 2007 [12] classification. A nontrivial proportion of moderate COPD patients $(17.4 \%)$ reported a limitation of functions affecting their daily independence. When considering daily life activities, one third of the observed patients lost at least 2 of the 8 explored functions. Interestingly, in our cohort, disabled patients did not differ from nondisabled ones for working status, smoking habit and level of bronchial obstruction, as expressed by the $\mathrm{FEV}_{1} \%$ predicted. This observation is in contrast with previous findings [21] showing that smoking habit strongly predicts disability retirement due to COPD.

Disability impacts the individual perspective of COPD in terms of illness perception, well-being and health status. Disabled patients described more COPD-related symptoms, perceived their illness as more cyclical and ascribed more severe consequences to COPD; moreover, they felt less confident regarding the possibility of controlling COPD and had more difficulties in understanding their disease. Disabled patients reported lower levels of vitality, general health, self-control and positive wellbeing, and higher levels of depressed mood and anxiety, all of which result in a lower personal well-being. Furthermore, both the physical and mental components of health status resulted in more impairment. These data are in line with those recently published by other researchers [22].

While $\mathrm{FEV}_{1}$, ranging from 55 to $73 \%$ of the predicted value in our population, did not significantly differ in disabled and nondisabled patients, disability was significantly associated with the risk of death due to comorbidities and dyspnea burden, the latter resulting as the dominant factor. We therefore evaluated whether a patient's classification 
according to $\mathrm{FEV}_{1} \%$ predicted and $\mathrm{mMRC}$ score, with the approach proposed by the GOLD 2011 [1] recommendations, could be useful for identifying disabled patients in daily practice. Our analysis showed that in patients with an mMRC score $<2$ the proportion of disabled patients is very small (near 2\%), while it increases to $20 \%$ among those with an $\mathrm{mMRC}$ score $\geq 2$. The odds ratio of being disabled grew impressively according to the mMRC score, whereas spirometric and risk-of-death parameters did not.

The cross-sectional nature of this study allowed us to describe a phenomenon (presence and burden of disability) and to assess its association with clinical features (comorbidities, airway obstruction severity and sociodemographic parameters) and patients' subjective experience (illness perception, well-being and health status) without permitting us to explore causal relationships. Moreover, we adopted two widely used generically validated tools to assess disability. A recent review [23] showed that none of the tools available for assessing disability in COPD patients can be considered as a gold standard. A specific questionnaire assessing COPD-related disability has been recently developed and validated [24], although it is not yet available in different languages; this tool could help the enhancement of COPD management by integrating an evaluation of the COPD-related disability into daily practice. After a careful investigation of the available tools, we chose the Barthel index for several reasons: an Italian version is available, it has been used previously with COPD patients and, given the criteria for inclusion in and exclusion from the study, it allowed us to assess disability in general and not only disability strictly related to COPD.

The present study underlined that the evaluation and classification of COPD patients can benefit from the use of additional, nonfunctional measures. The mMRC score was found to be the most relevant factor related to disability in COPD patients. The determinants of symptoms are various and include physiological, psychological, social and environmental factors that interact, thus affecting both the quality and intensity of symptom perception [25]. The presence of disability appeared to significantly affect different aspects of illness perception; this is expected to worsen patients' quality of life.

The results of this study show that a significant proportion of COPD patients with moderate airflow obstruction report limitations affecting their daily independence, with dyspnea serving as the most relevant factor inducing disability. Patients' stratification according to $\mathrm{FEV}_{1}$ values and mMRC score (cutoff score $\geq 2$ or median value) was found to be effective in identifying disabled patients, while mMRC values were associated with the risk of disability.

\section{Acknowledgements}

The authors wish to thank SIMeR (Società Italiana di Medicina Respiratoria), ARMIA (Associazione Ricerca Malattie Immunologiche e Allergiche) and ASPADIRES (Associazione Pazienti Disturbi Respiratori nel Sonno) and acknowledge linguistic assistance by Dr. Marianna Bruzzone when preparing the manuscript.

\section{References}

1 Global Initiative for Chronic Obstructive Lung Disease (GOLD): Global Strategy for the Diagnosis, Management and Prevention of COPD. www.goldcopd.com/guidelines-global-strategy-for-diagnosis-management.html.

-2 Han MK, Muellerova H, Curran-Everett D, Dransfield MT, Washko GR, Regan EA, Bowler RP, Beaty TH, Hokanson JE, Lynch DA, Jones PW, Anzueto A, Martinez FJ, Crapo JD, Silverman EK, Make BJ: GOLD 2011 disease severity classification in COPDGene: a prospective cohort study. Lancet Respir Med 2013;1:43-50.

-3 Regan EA, Hokanson JE, Murphy JR, Make B, Lynch DA, Beaty TH, Curran-Everett D, Silverman EK, Crapo JD: Genetic epidemiology of COPD (COPDGene) study design. COPD 2010;7:32-43.

4 Lange P, Marott JL, Vestbo J, Olsen KR, Ingebrigtsen TS, Dahl M, Nordestgaard BG: Prediction of the clinical course of chronic ob- structive pulmonary disease, using the new GOLD classification. Am J Respir Crit Care Med 2012;186:975-981.

5 Soriano JB, Alfageme I, Almagro P, Casanova C, Esteban C, Soler-Cataluña JJ, de Torres JP, Martinez-Camblor P, Miravitlles M, Celli BR, Marin JM: Distribution and prognostic validity of the new global initiative for chronic obstructive lung disease grading classification. Chest 2013;143:694-702.

-6 Johannessen A, Nilsen RM, Storebø M, Gulsvik A, Eagan T, Bakke P: Comparison of 2011 and 2007 Global Initiative for Chronic Obstructive Lung Disease guidelines for predicting mortality and hospitalization. Am J Respir Crit Care Med 2013;188:51-59.

$>7$ Leivseth L, Brumpton BM, Nilsen TI, Mai XM, Johnsen R, Langhammer A: GOLD classifications and mortality in chronic obstructive pulmonary disease: the HUNT Study, Norway. Thorax 2013;68:914-921.
8 Yohannes AM: Disability in patients with COPD. Chest 2014;145:200-202.

$\checkmark$ Braido F, Baiardini I, Menoni S, Bagnasco AM, Balbi F, Bocchibianchi S, Balestracci S, Piroddi MG, Canonica GW: Disability in COPD and its relationship to clinical and patient-reported outcomes. Curr Med Res Opin 2011;27:981-986.

$>10$ Atsou K, Chouaid C, Hejblum G: Variability of the chronic obstructive pulmonary disease key epidemiological data in Europe: systematic review. BMC Med 2011;18:7.

11 Troosters T, van der Molen T, Polkey M, Rabinovich RA, Vogiatzis I, Weisman I, Kulich K: Improving physical activity in COPD: towards a new paradigm. Respir Res 2013;14:115.

12 From the Global Strategy for the Diagnosis, Management and Prevention of COPD, Global Initiative for Chronic Obstructive Lung Disease (GOLD) 2007. http://www. goldcopd.org/. 
13 Miller MR, Hankinson J, Brusasco V, Burgos F, Casaburi R, Coates A, Crapo R, Enright P, van der Grinten $\mathrm{CP}$, Gustafsson P, Jensen R, Johnson DC, MacIntyre N, McKay R, Navajas D, Pedersen OF, Pellegrino R, Viegi G, Wanger J; ATS/ERS Task Force: Standardisation of spirometry. Eur Respir J 2005;26:319-338.

14 Mahoney FI, Barthel DW: Functional evaluation: the Barthel index. Md State Med J 1965; 14:61-65.

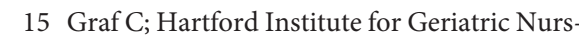
ing: The Lawton instrumental activities of daily living (IADL) scale. Medsurg Nurs 2008; 17:343-344.

16 Charlson ME, Pompei P, Ales KL, MacKenzie CR: A new method of classifying prognostic comorbidity in longitudinal studies: development and validation. J Chronic Dis 1987;40: 373-383.

17 Miller MR, Hankinson J, Brusasco V, Burgos F, Casaburi R, Coates A, Crapo R, Enright P, van der Grinten CP, Gustafsson P, Jensen R, Johnson DC, MacIntyre N, McKay R, Navajas D, Pedersen OF, Pellegrino R, Viegi G, Wanger J; ATS/ERS Task Force: Standardisation of spirometry. Eur Respir J 2005;26:319-338.
18 Moss-Morris R, Weinman J, Petrie K, Horne $\mathrm{R}$, Cameron LD, Buick D: The revised illness perception questionnaire (IPQ-R). Psychol Health 2002;17:116.

19 Dupuy HJ: The psychological general wellbeing (PGWB) index; in Wenger NK, Mattson ME, Furberg CD, Elinson J (eds): Assessment of Quality of Life in Clinical Trials of Cardiovascular Therapies. New York, Le Jacq Publishing, 1984, pp 170-183.

20 Ware J Jr, Kosinski M, Keller SD: A 12-item short-form health survey: construction of scales and preliminary tests of reliability and validity. Med Care 1996;34:220-233.

21 Hukkinen M, Korhonen T, Heikkilä K, Kaprio J: Association between smoking behavior patterns and chronic obstructive pulmonary disease: a long-term follow-up study among Finnish adults. Ann Med 2012;44: 598-606.
22 Rodríguez-Rodríguez P, Jiménez-García R, Hernández-Barrera V, Carrasco-Garrido $\mathrm{P}$, Puente-Maestu L, de Miguel-Díez J: Prevalence of physical disability in patients with chronic obstructive pulmonary disease and associated risk factors. COPD 2013;10:611617.

23 Janaudis-Ferreira T, Beauchamp MK, Robles PG, Goldstein RS, Brooks D: Measurement of activities of daily living in patients with COPD: a systematic review. Chest 2014; 145 : 253-271.

24 Aguilaniu B, Gonzalez-Bermejo J, Regnault A, Barbosa CD, Arnould B, Mueser M, Granet G, Bonnefoy M, Similowski T: Disability Related to COPD Tool (DIRECT): towards an assessment of COPD-related disability in routine practice. Int J Chron Obstruct Pulmon Dis 2011;6:387-398.

-25 Locke E, Thielke S, Diehr P, Wilsdon AG, Graham Barr R, Hansel N, Kapur VK, Krishnan J, Enright P, Heckbert SR, Kronmal RA, Fan VS: Effects of respiratory and non-respiratory factors on disability among older adults with airway obstruction: the Cardiovascular Health Study. COPD 2013;10:588-596. 